Proceedings

\title{
Beyond environmental protection and conservation: local-level implementation of the 2030 Agenda to deliver universal goals and targets: Lessons from Sardinia, Italy
}

\author{
Francesca Leccis ${ }^{1}$
}

Department of Civil and Environmental Engineering, and Architecture. University of Cagliari, Italy; francescaleccis@unica.it

Abstract: According to the 2030 Agenda, sustainability is no longer restricted to environmental protection and conservation, but it also needs to consider economic and social issues. This poses new challenges to urban planning and territorial management, that require new procedures to practically implement the global goals into local policies to effectively deal with counteractive priorities. This study proposes an innovative approach aimed at harmonizing local plans and the Sardinia's Regional Strategy for Sustainable Development. A new tool, which integrates the objectives of the Regional Strategy for Sustainable Development into local plans and simultaneously assesses the efficiency of these strategies in the related spatial context is defined and applied.

Keywords: Sustainable and Inclusive planning, 2030 Agenda, National Sustainable Development Strategy, Regional Strategy for Sustainable Development.

Citation: Leccis, F., 2022, Beyond environmental protection and conservation: local-level implementation of the 2030 Agenda to deliver universal goals and targets: Lessons from Sardinia, Italy. SUPTM 2022 conference proceedings sciforum-052961. https://doi.org/10.31428/10317/10596

Publisher's Note: UPCT and Sciforum stays neutral with regard to jurisdictional claims in published maps and institutional affiliations.

Copyright: (c) 2022 by the authors. Submitted for possible open access publication under the terms and conditions of the Creative Commons Attribution (CC BY) license (https://creativecommons.org/license s/by/4.0/).

\section{Introduction}

According to the 2030 Agenda, sustainability is no longer restricted to environmental protection and conservation, but it also needs to consider economic and social issues (UNDP, 2021, UNGA, 2015). This poses new challenges to urban planning and territorial management, since counteractive priorities have to be addressed. In particular, the agenda identifies 17 Sustainable Development Goals and 169 targets to stimulate action in five areas of critical importance for humanity and the planet, with the aim of eradicating poverty, improving health and education, reducing inequality, spurring economic growth, tackling climate change and preserving oceans and forests (UNGA, 2015). In order to be operational and effective, the agenda needs to be geared to the national and regional context and integrated into local plans.

For this reason, the Italian government approved the National Sustainable Development Strategy (MiTE, 2021), while the Autonomous Region of Sardinia defined the Regional Strategy for Sustainable Development (RAS, 2021). Moreover, the implementation of policy instruments to pursue the objectives set in the Regional Strategy is appointed by the Italian legislative decree 152/2006 to Local Governments. However, procedures to practically implement the global goals into local policies still need substantial enhancement to effectively deal with counteractive priorities (Weymouth and Hartz-Karp, 2018). Consequently, new methodological tools should be operationalized to steer local plans towards the framework of the aforementioned dimensions of sustainability.

This study proposes an innovative approach aimed at harmonizing local plans and the Sardinia's Regional Strategy for Sustainable Development. A new tool, which integrates the objectives of the Regional Strategy for Sustainable Development (RSSD) into local plans and simultaneously assesses the efficiency of these strategies in the related spatial context is defined and applied to a case study. In this way, environmental, social and economic dimensions of sustainability are taken into account and implemented into local plans in terms of objectives, actions and indicators, as a result of an inclusive 
governance model characterized by active participation of the public, private profit and 1 non-profit sectors, voluntary organizations and citizens' movements.

This paper is structured into five sections: this introduction, the description of the area of study, the illustration of the developed methodology, the presentation of the results and the drawing of final conclusions.

\section{Area of study}

This study proposes a pioneering approach to integrate the RSSD defined by the Italian Autonomous Region of Sardinia into local plans and programs. Sardinia is the second largest island in the Mediterranean Sea, located west of the Italian peninsula (Figure 1).

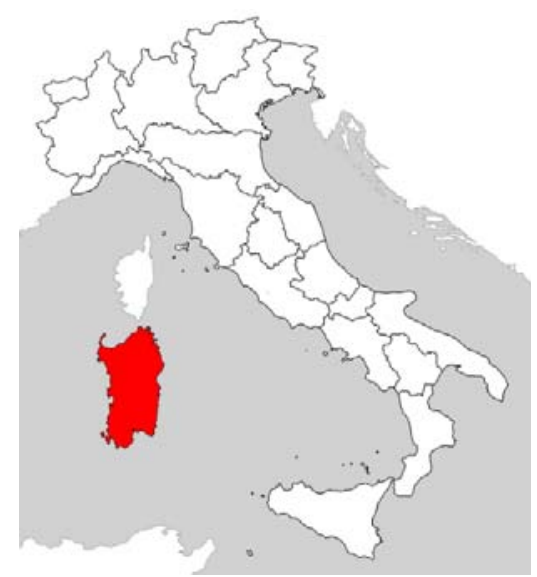

Figure 1. Italy's map. In red the Autonomous Region of Sardinia (Author's elaboration).

In particular, the preliminary municipal masterplan (MMP) of the Municipality of Cagliari is defined. Cagliari is the capital city of the Sardinian region and it is located at the northern extremity of the Gulf of Cagliari, on the south coast of the island (Figure 2).

Figure 2. Location of the case study in Sardinia's map. (Author's elaboration).

\section{Methodology}

The proposed methodology builds on a model of strategic environmental assessment which simultaneously takes into account environmental concerns as well as social and economic issues by integrating the Sardinian RSSD in the perspective preliminary MMP of the Municipality of Cagliari. In particular, the developed approach stems from the Logical Framework Approach (LFA), which displays the logic connections among plan objectives and activities (Las Casas and Scorza, 2016) and highlights relations between project elements and external features, thus emphasizing the strategy dimension and allowing for continuous monitoring (NORAD, 1999). Figure 3 shows the process of definition of the logical framework, which includes four phases: the definition of the sustainability- 
oriented objectives, the assessment of policy consistency, the definition of the specific objectives and the definition of the actions. It can be observed that the RSSD informs the definition of the sustainability-oriented objectives, of the specific objectives and of the actions, thus embedding the environmental, social and economic concerns identified in the RSSD in the perspective plan.

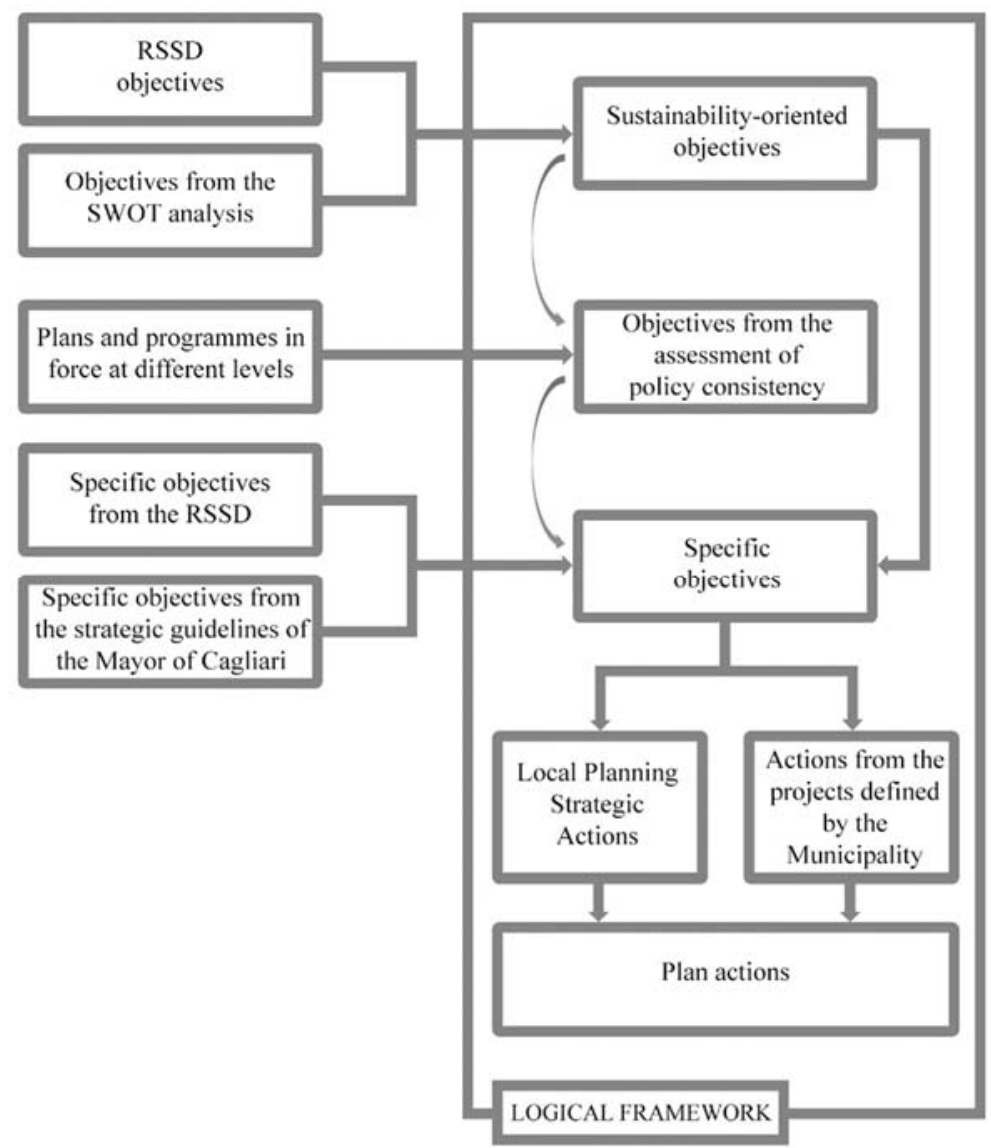

Figure 3. The process of definition of the Logical Framework (Author's elaboration).

\section{Results}

By applying the process illustrated above, objectives and actions of the preliminary MMP of Cagliari are defined. Table 1 shows an excerpt of the logical framework related to the preliminary MMP of Cagliari.

Table 1. Excerpt of the logical framework related to the MMP of Cagliari.

\section{Sustainability-oriented objectives}

\section{Actions}

Projects to improve slow mobility infrastructure (bike lanes, pedestrian areas, etc.).

Improvement of sustainable mobility infrastrucImprovement of ture (carsharing parking spaces; bike racks; segTo promote and enhance road infrastructure way, hoverboard, bike and kick scooter rental arlocal public transports and and of the efficiency the sustainable urban mo- of the sustainable urbility system. ban mobility system.

$$
\text { eas). }
$$

Delimitation of new

restricted traffic areas.

Realization of new multi-modal transport nodes and parking spaces (park and ride).

Management of the interface areas. 


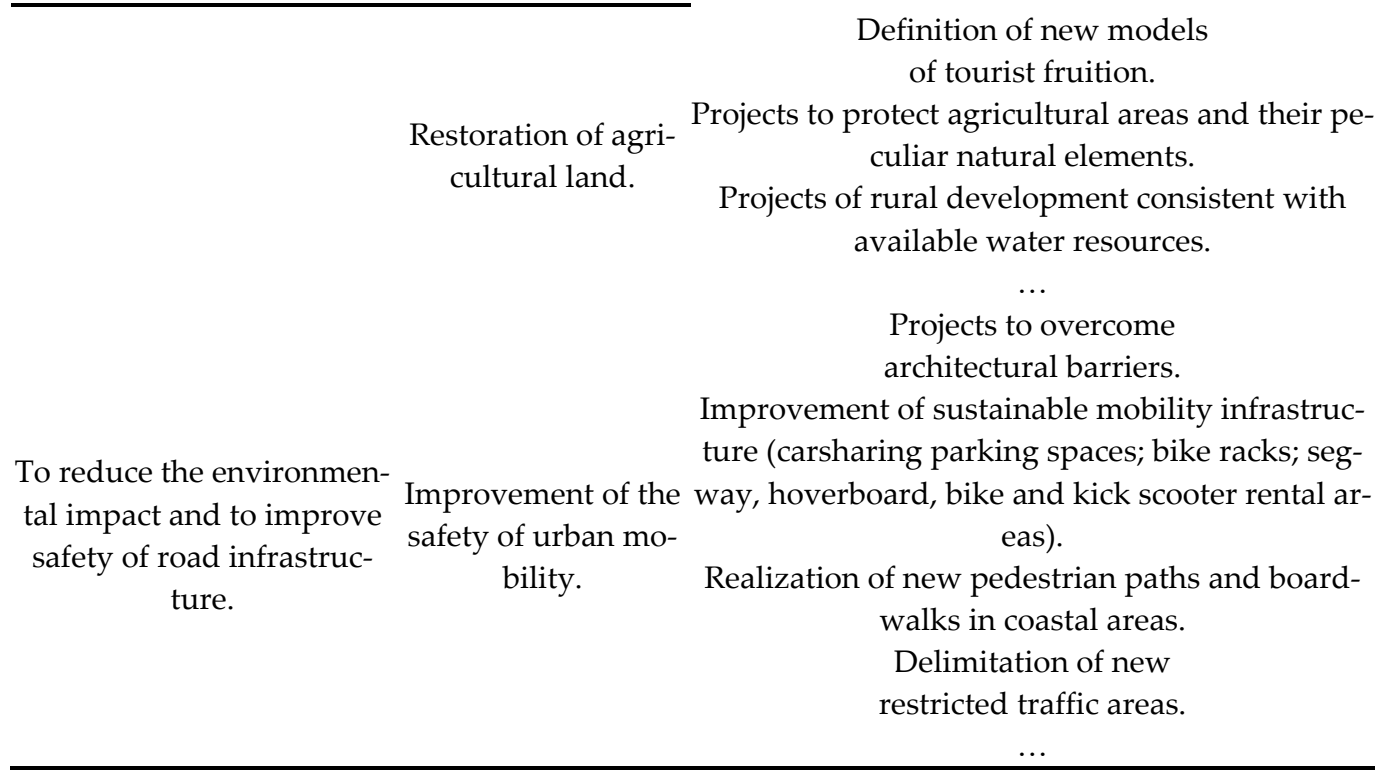

\section{Conclusions}

Following the definition of sustainability introduced by the 2030 Agenda, which includes economic, social and environmental aspects, this paper proposes an innovative procedure of urban planning to integrate the RSSD in urban and regional planning practices. In particular, it enriches the process of strategic environmental assessment by developing a pioneering methodological approach, based on the LFA, that leads to the definition of the plan objectives and actions that include aspects from both the SWOT analysis and the RSSD. This methodology is applied to the definition of the preliminary MMP of the Municipality of Cagliari, but it is replicable in other contexts for the definition of urban and regional plans at different levels.

Funding: This research is implemented within the research project SOSLabs. Laboratori di ricercaazione per la Sostenibilità urbana" [SOSLabs. Research-action laboratories for urban sustainability], financed by the Ministry of the Environment and of the Protection of the Territory and the Sea of the Italian Government within the "Bando per la promozione di progetti di ricerca a supporto dell'attuazione della Strategia Nazionale per lo Sviluppo Sostenibile - Bando Snsvs 2" ["Public selection for the promotion of research projects focusing on the implementation of the National Strategy for sustainable development - Public selection Snsvs 2"'].

Conflicts of Interest: The authors declare no conflict of interest.

\section{References}

1. Background on the goals. Available online: https://www.undp.org/content/undp/en/home/sustainable-developmentgoals/background/ (accessed on 30/11/2021).

2. UNGA (General Assembly of the United Nation); Transforming our world: the 2030 Agenda for Sustainable Development. United Nations, 2015.

3. Strategia Nazionale per lo Sviluppo Sostenibile. Available online: https://www.mite.gov.it/pagina/strategia-nazionale-losviluppo-sostenibile (accessed on 13/12/2021).

4. Sardegna2030 - Strategia Regionale di Sviluppo Sostenibile. Available online: https://www.regione.sardegna.it/argomenti/strategiaregionalesvilupposostenibile/ (accessed on 13/12/2021).

5. Weymouth, R. and Hartz-Karp Janette, H.-K. Principles for Integrating the Implementation of the Sustainable Development Goals in Cities. US 2018, 2, 77. https://doi.org/10.3390/urbansci2030077.

6. Las Casas, G., \& Scorza, F. Sustainable Planning: A Methodological Toolkit. In International Conference on Computational Science and Its Applications, ICCSA 2016. Lecture Notes in Computer Science. Gervasi O., Murgante B., Misra S., Rocha A.M.A.C., Torre C., Taniar D., Apduhan B.O., Stankova E., Wang S., Eds.; Springer International Publishing: Cham, 2016; volume 9786, pp. 627-635.

7. NORAD (Norwegian Agency for Development Cooperation). The Logical Framework Approach (LFA): Handbook for Objectives-oriented Planning, 4th ed; NORAD: Oslo, 1999. 